\title{
Cytoskeleton in Human Mammary Carcinoma Cells Forming Three-Dimensional Cellular Structures within Collagen Gels
}

\author{
Kazuhide Takahashi ${ }^{1}$ and Tetsuo Ono \\ Department of Biochemistry, Kanagawa Cancer Center Research Institute, 54-2 Nakao-cho, Asahi-ku, \\ Yokohama 241, Japan
}

Key words: morphogenesis/cytoskeleton/collagen gel culture/mammary carcinoma cells

\begin{abstract}
Human mammary carcinoma cell line MCF-7 cells grown on type I collagen gels floating in a medium occasionally invaginated into the gels as a cell mass and formed cylindrical or domed structures within it. The $0.05 \%$ Triton-insoluble cytoskeleton of such cellular structures sedimented as a white flocculent layer at the boundary between 60 and 70\% sucrose layers by ultracentrifugation, and consisted of 4 basal components: $54-$ $\mathrm{kD}(\beta$-tubulin), 45-kD, 42-kD (actin), and 39-kD polypeptides. By contrast, the isolated cytoskeleton of MCF-7 cells grown as monolayers on plastic substratum formed a finer cytoskeletal network with a smaller buoyant density and consisted of two distinct polypeptides with apparent molecular sizes of $80-\mathrm{kD}$ and $65-\mathrm{kD}$ in addition to the 4 basal components found in the morphologically developing cells. The present results indicate that the cytoskeleton of MCF-7 cells forming the three-dimensional cellular structures within collagen gels is lacking in these two polypeptides, and that it has a coarser cytoskeletal network with a greater buoyant density than that of the monolayered cells on plastic.
\end{abstract}

The mammary gland, which grows and forms a branched ductal structure within fat tissues during adolescence in the female (19), provides a complex and yet versatile model for studies of hormonal responsiveness, functional differentiation, and morphogenesis of mammary epithelial cells. Most of the early studies on the morphogenesis of this gland were performed either in vivo (4) or in organotypic cultures (7). Subsequent investigations in vitro using collagen gels as an extracellular matrix in place of fat tissues showed that mammary epithelial cells could proliferate and morphologically develop to produce three-dimensional structures $(5,16-$ 18, 24). This indicated that the differentiated function of the cells was retained or could be induced in such cells if the environment was correct. In fact, investigators using a variety of culture supplements succeeded in growing cells retaining certain functions. However, there is little known about the molecular aspects of cellular factors participating in the morphological development of the mammary epithelial cells.

Cytoskeletal components, including microtubules, actin filaments (3), and intermediate filaments (9), are generally thought to be involved in the morphological development of cells. The present study induces morphological development in human mammary carcinoma cell line MCF-7 cells in order to examine their cytoskeletal

\footnotetext{
1 To whom correspondence should be addressed.
}

components and compare the results with those on cells grown as monolayers. MCF-7 cells seeded on type I collagen gels occasionally invaginated into the gels as a cell mass. Our study demonstrates that the three-dimensional structures formed are comprised of 4 basal components, including $\beta$-tubulin and actin, but that they were void of the two other components found in monolayer cultures.

\section{MATERIALS AND METHODS}

Monolayer culture of $M C F-7$ cells. Human mammary carcinoma cell line MCF-7 cells were cultivated in RPMI-1640 medium supplemented with 10\% FCS (HyClone Laboratories, Inc., Logan, UT) and $10^{-8} \mathrm{M} 17 \beta$-estradiol (Sigma Chemical Co., St. Louis, MO) in plastic tissue culture dishes (Greiner, Nurtigen, FRG).

Culture of MCF7 cells on collagen gels. For standard culture using collagen gels, a collagen layer $(0.5 \mathrm{ml})$ was formed in each well of 24-well plastic plates (Greiner) by mixing in the cold 7 volumes of $0.3 \%$ acid-soluble type I collagen solution (Cellmatrix type I-A, Nitta Gelatin, Osaka, Japan), two volumes of 5-fold concentrated medium, and one volume of $0.08 \mathrm{~N} \mathrm{NaOH}$ in $0.2 \mathrm{M} \mathrm{N}$-2-hydroxyethylpiperadin-N'-2ethanesulfonic acid (HEPES). Cells grown as monolayer cultures were harvested by treatment with $0.25 \%$ trypsin and $0.1 \%$ EDTA (Sigma Chemical Co.), and the number of viable cells was counted by a hemocytometer. Cell density was ad- 
justed to $10^{6} / \mathrm{ml}$ and a $10-\mu 1$ drop of the cell suspension was placed onto each $0.5-\mathrm{ml}$ collagen gel layer. After the culture plates had been kept at $37^{\circ} \mathrm{C}$ for $2 \mathrm{~h}$, the cells in each well were flooded with $1 \mathrm{ml}$ of culture medium.

Each collagen gel layer was detached from the plastic plates after confluence of cells on the gels had been achieved. Medium change was performed every second day throughout the culture period.

Histology. For histological observation, cells in collagen layers were fixed with $10 \%$ buffered-formalin, dehydrated, and embedded in paraffin. Sections at $4 \mu \mathrm{m}$ were stained with hematoxylin and eosin.

Preparation of isolated cytoskeleton. Cells grown in monolayer cultures at near confluence were rinsed twice with PBS and harvested with a rubber policeman, followed by centrifugation in stabilizing buffer (8), designated as SB and con- sisting of $0.15 \mathrm{M} \mathrm{NaCl}, 1 \mathrm{mM} \mathrm{MgCl}_{2}, 1 \mathrm{mM}$ EGTA, $2 \mathrm{mM}$ ATP, $20 \mathrm{mM}$ HEPES (pH 6.9), and $0.5 \mathrm{mM}$ phenylmethanesulfonyl fluoride (PMSF). Then the cells were lysed in 5 volumes of SB containing $0.05 \%$ Triton $\mathrm{X}-100$ and $30 \%$ glycerin (8) and homogenized in a Dounce homogenizer by 5 strokes with a tight-fitting pestle at room temperature $\left(20^{\circ} \mathrm{C}\right)$.

MCF-7 cells that had invaginated into collagen gels and formed cylindrical or domed cell structures were rinsed twice with PBS and dissected from the collagen gels into small fragments in SB. Thus dissected, the gel fragments containing the cell structures were gently vortexed in SB containing Triton X-100 and glycerin. After removal of the collagen gels by centrifugation at $3,000 \mathrm{rpm}$ for $10 \mathrm{~min}$ at room temperature, cells were Dounce-homogenized as described above. The cytoskeleton was isolated through a discontinuous sucrose gradient composed of $1 \mathrm{ml}$ each of $40,50,60,70$, and $80 \%$

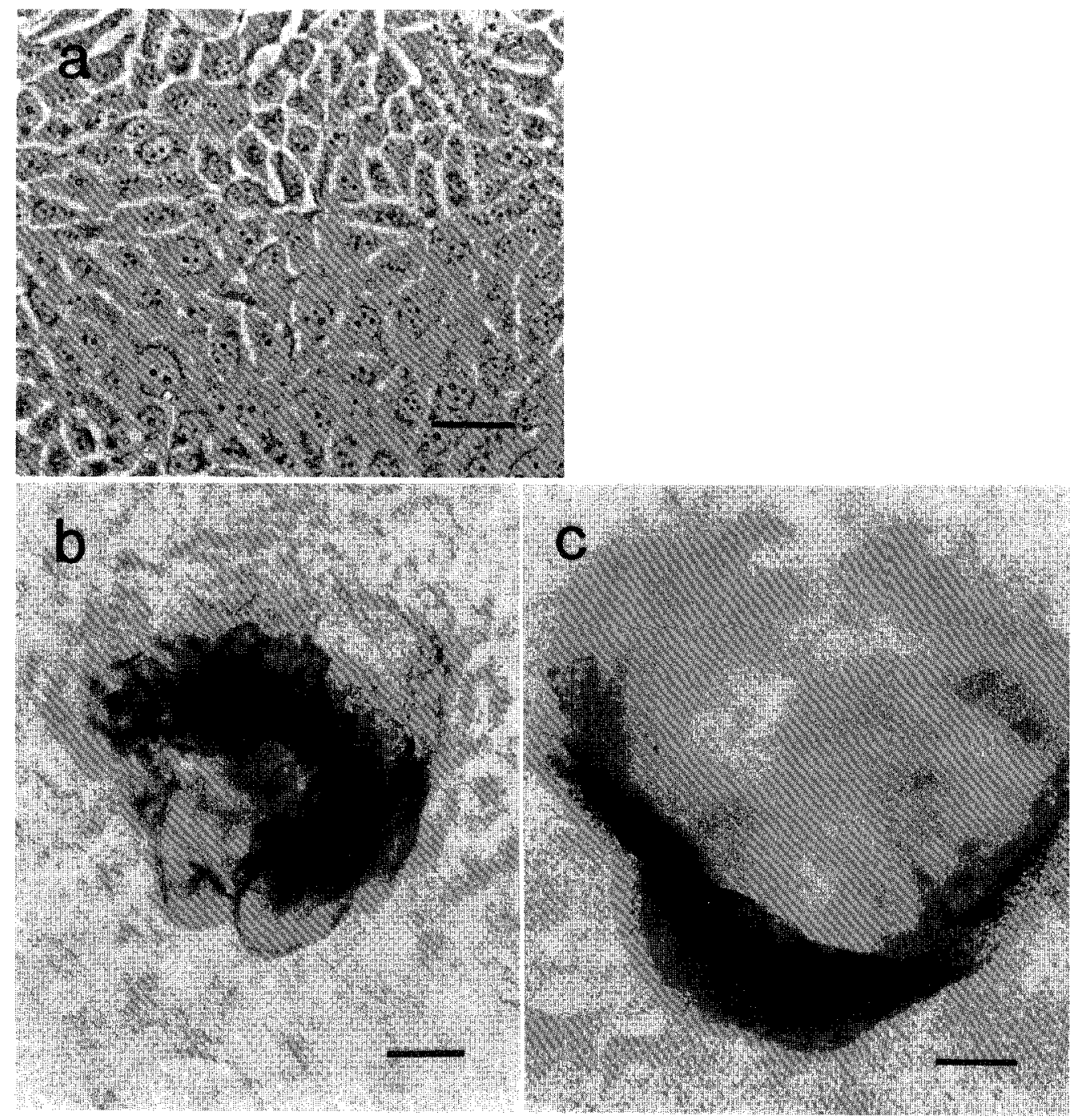

Fig. 1. Phase-contrast photomicrographs of MCF-7 cells grown on a plastic dish in monolayer culture (a) or on collagen gels and forming a cylindrical (b) or a domed (c) cellular structure. Note that the collagen gel layer is turned upside down in (b). Bar, $50 \mu \mathrm{m}$ (a); $200 \mu \mathrm{m}$ (b) and (c). 
sucrose in SB by centrifugation at $150,400 \mathrm{~g}(40,000 \mathrm{rpm})$ for $1 \mathrm{~h}$ at $20^{\circ} \mathrm{C}$ in a centrifuge (model $\mathrm{SCP} 70 \mathrm{H}$, Hitachi Koki Co., Tokyo, Japan) equipped with an RPS50-2 rotor. Isolated cytoskeleton was identified as a white flocculent layer in the sucrose gradient.

Electron microscopy. For negative staining of the cytoskeleton, a drop of isolated cytoskeleton in sucrose solution was applied onto a carbon-coated collodion supporting film that had been treated with 5\% poly-L-lysine (Sigma Chemical Co.) solution. The preparations were then negatively stained with $6 \%$ uranyl acetate. Electron microscopy was performed with a Hitachi H7000 transmission electron microscope (Hitachi Ltd., Tokyo, Japan).

Two-dimensional gel electrophoresis. Two-dimensional gel electrophoresis was carried out as described by O'Farrel (15) by the use of Bio-Lite (Bio-Rad Laboratories, Richmond, $\mathrm{CA}$ ) having a $\mathrm{pH}$ range $3-10$. To determine the molecular size of proteins, we used an electrophoresis calibration kit (Pharmacia AB, Uppsala, Sweden) as internal markers. Gels were stained with Coomassie blue or with silver (14) by the use of a silver stain kit (Wako Pure Chemical Industries, Osaka, Japan).

Immunochemical detection of cytoskeletal components. The antibodies used included one polyclonal, anti-human vimentin (Chemicon International Inc., Temecula, CA) and 5 monoclonals: antikeratins, anti-tubulin ( $\beta$ chain) (Chemicon International Inc.), anti-alpha tubulin (Cedarlane Laboratories Ltd., Ontario, Canada), anti-actin (Amersham International plc, Buckinghamshire, England), and anti-vimentin (Labsystems Oy, Helsinki, Finland). For immunoprecipitation, the isolated cytoskeleton was suspended in $0.01 \mathrm{M}$ Tris$\mathrm{HCl}(\mathrm{pH} 7.4), 0.15 \mathrm{M} \mathrm{NaCl}, 1 \%$ sodium deoxycholate, $1 \%$ Triton X-100, 0.1\% SDS, and $1 \mathrm{mM} \mathrm{PMSF}$. Antibodies were added, and the mixture was incubated at room temperature for $90 \mathrm{~min}$. Then a slurry of Protein A Sepharose (Pharmacia $A B)$ was added and incubation continued for another $60 \mathrm{~min}$. Finally, the Sepharose was washed 4 times by centrifugation with PBS (pH 8.6), containing 0.5\% NP-40 and 0.1\% SDS.

In some experiments, the cytoskeletal proteins separated in SDS-polyacrylamide gels were electrophoretically transferred (20) onto a polyvinylidene difluoride membrane (Millipore Corp., Bedford, MA) (10). The cytoskeletal components transferred onto the membrane were incubated with each of the antibodies in $0.1 \mathrm{M}$ Tris- $\mathrm{HCl}(\mathrm{pH} 7.5), 0.1 \%$ Tween 20 , and $0.9 \% \mathrm{NaCl}$ at room temperature for $1 \mathrm{~h}$. The reactivities of the antibodies were visualized with a Vectastain $A B C$ Kit (Vector Laboratories, Burlingame, CA), which utilizes an avidin-biotin amplification procedure (6).

\section{RESULTS}

Morphology. Human mammary carcinoma cell line MCF-7 cells assume an epithelial-like morphology on the surface of plastic culture dishes containing growth medium (Fig. 1a). Under the culture conditions employed in the present study, no morphological development could be induced in cells even after the confluence of cells on plastic dishes.

When cells were seeded on type I collagen gels, they grew as multilayers and formed a round sheet of cells after a 3- or 4day culture period. One week after the collagen gels were detached from the plastic plates, the cell mass at the central region of the cellular sheet occasionally invaginated into the floating gel and formed a cylindrical (Fig. 1b) or domed cellular structure (Fig. 1c) within the gel. The incidence of such three-dimensional cell structures was in the range of 20 to $50 \%$ of the cultures.

Histology. Microscopic observation of longitudinal sections demonstrated that a representative cylindrical structure formed by MCF-7 cells projected downward into the collagen gel layer (Fig. 2a). An enlargement of the area designated by
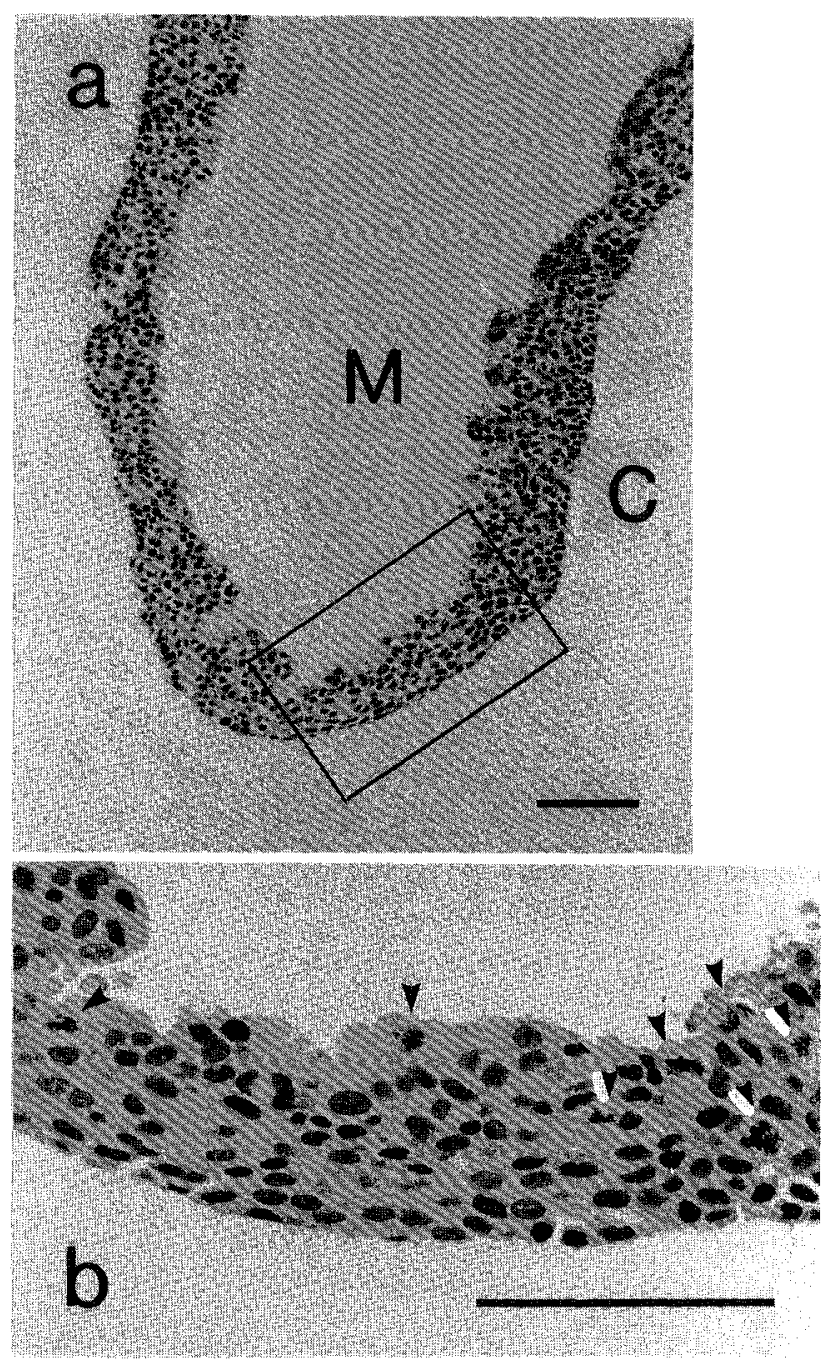

Fig. 2. Micrograph of hematoxylin- and eosin-stained longitudinal section of a cylindrical structure of MCF-7 cells in a collagen gel (a). Medium (M); collagen gel (C). The region in the box in (a) is enlarged below (b). Arrowheads indicate mitotic cells. Bars, $100 \mu \mathrm{m}$. 
the rectangle in Fig. 2a shows that there were many mitotic cells in the apical region of the cylindrical structure and that cells facing toward the collagen layer were flattened (Fig. 2b). Cross sections revealed that the cylindrical structure was composed of a cell layer consisting of multilayers of cells with varied thickness and that many small duct-like structures were contained in the cell layer (Fig. 3a). Formation of the early duct-like structures defined by 10 to 20 cells was more discernible in small lamellar structures protruding along the large cylindrical one (Figs. $3 \mathrm{~b}$ and c). These structures resemble the histological features of intraductal carcinomas of human breast cancer.

Isolation of Cytoskeleton. MCF-7 cells grown as monolayers on the plastic dishes were harvested and lysed with $0.05 \%$ Triton X-100-containing solution. The detergent-insoluble cytoskeleton mainly sedimented as a white flocculent layer at the boundary between 50 and $60 \%$ sucrose layers with some portions being distributed in the $60 \%$ sucrose layer after ultracentrifugation (Fig. 4, left). Contrary to this, the $0.05 \%$ detergent-insoluble cytoskeleton of $\mathrm{MCF}-7$ cells forming three-dimensional cellular structures sedimented at the boundary between 60 and $70 \%$ sucrose layers (Fig. 4, right).

Electron Microscopy of Cytoskeleton. Negative staining of the cytoskeleton isolated from MCF-7 cells in monolayer cultures as the $0.05 \%$ Triton-insoluble fraction assumed a fine network morphology and there were no obvious fibrous struc- tures (Fig. 5a). The cytoskeleton isolated from morphologically developing MCF-7 cells was coarser than that isolated from monolayer-cultured cells (Fig. 5b).

Two-dimensional Gel Electrophoresis. The cytoskeleton that sedimented as a white flocculent layer in the sucrose gradient was collected and analyzed by two-dimensional gel electrophoresis. The cytoskeleton from MCF-7 cells in monolayer cultures consisted of several prominent polypeptides with apparent molecular sizes of 80-, 65-, 54-, 45-, 42-, and 39-kD (Fig. 6a). By contrast, the cytoskeleton of morphologically developing celis within collagen gels virtually consisted of 4 prominent polypeptides with apparent molecular sizes of 54-, 45-, $42-$, and $39-\mathrm{kD}$, while the other two polypeptides with apparent molecular sizes of $80-\mathrm{kD}$ and $65-\mathrm{kD}$ were only trace components (Fig. 6b). The gel patterns of the cytoskeletal components of MCF-7 cells grown under either culture conditions were highly reproducible.

Among the $0.05 \%$ Triton-insoluble cytoskeletal components from MCF-7 cells grown in monolayer cultures, the 54$\mathrm{kD}$ polypeptide reacted with anti-tubulin ( $\beta$ chain) antibody when assayed by immunoprecipitation (Fig. 7a). This polypeptide was also recognized by the same antibody by the immunostaining assay after blotting onto a transfer membrane. A polypeptide with an apparent molecular size of $42-\mathrm{kD}$ was found to react with anti-actin antibody (Fig. 7b). The cytoskeletal components other than the $54-\mathrm{kD}$ and $42-\mathrm{kD}$ polypep-
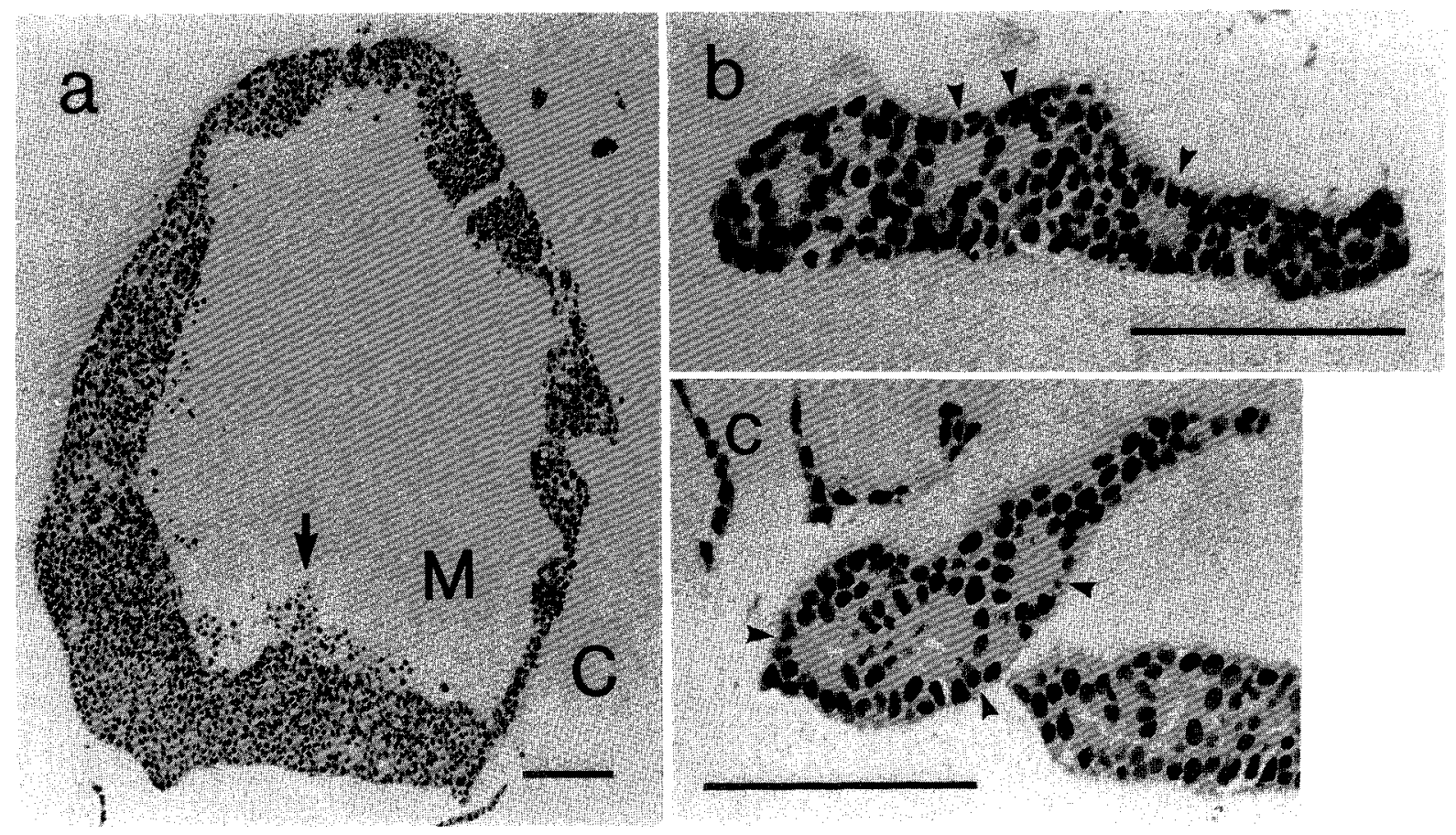

Fig. 3. Micrograph of hematoxylin- and eosin-stained cross section of a cylindrical cell structure formed by MCF-7 cells grown in collagen gel (a). Medium (M); collagen gel (C). The arrow indicates the many necrotic cells inside of the structure. Micrographs of hematoxylin- and eosinstained cross sections of small lamellar structures $(b, c)$, protruding along the large cylindrical structure shown in (a). Arrowheads indicate early ductal structures composed of 10 to 20 cells. Bar, $100 \mu \mathrm{m}$. 


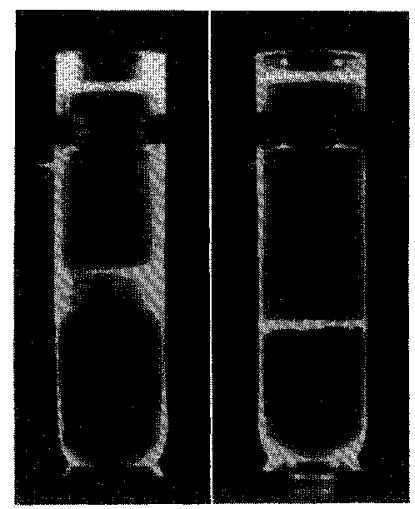

Fig. 4. Ultracentrifugation of the $0.05 \%$ Triton-insoluble cytoskeleton through a discontinuous sucrose gradient. The cytoskeleton isolated from MCF-7 cells grown in monolayer cultures (left) or on collagen gels and forming cylindrical or domed structures (right) was separated by ultracentrifugation.

tides failed to react with the antibodies used, which included anti-cytokeratins, anti-tubulin ( $\alpha$ chain), and anti-vimentin (data not shown).

Cytoskeletal Components in Total Polypeptide Fraction. To examine whether the $80-\mathrm{kD}$ and $65-\mathrm{kD}$ polypeptides that are virtually absent in $0.05 \%$ Triton-insoluble cytoskeletal components in morphologically developing cells are present but are soluble to the detergent, MCF-7 cells grown under either culture conditions were directly lysed and analyzed by two-dimensional gel electrophoresis. Of the total polypeptide fraction of cells grown as a monolayer, the relative amounts of each of the cytoskeletal components, including the $80-\mathrm{kD}$ and $65-\mathrm{kD}$ polypeptides, were similar to those in the $0.05 \%$ Triton-insoluble fraction (Figs. 8a and d). Contrary to the total polypeptides derived from monolayer-cultured cells, the total polypeptide fraction of morphologically developing cells (Fig. 8b) also contained a large amount of polypeptides derived from the collagen gels (Fig. 8c). Subtraction of the collagen gel-derived polypeptides from the total polypeptide moiety revealed that the amount of both $80-\mathrm{kD}$ and $65-\mathrm{kD}$ polypeptides were also very small in the total cellular polypeptides (Fig. 8e) as were those in the $0.05 \%$ Triton-insoluble fraction.

\section{DISCUSSION}

Human mammary carcinoma cell line MCF-7 cells grown on plastic dishes formed no three-dimensional cellular structures. However, when seeded on collagen gels on plastic plates, from which they subsequently detached on growth medium, they occasionally invaginated into the gels as a cell mass to produce cylindrical or domed structures within it. This result suggests that MCF-7 cells retain at least part of their potential to morphologically develop within collagen gels in spite of their histological resemblance to intraductal carcinomas rather than normal mammary gland cells.

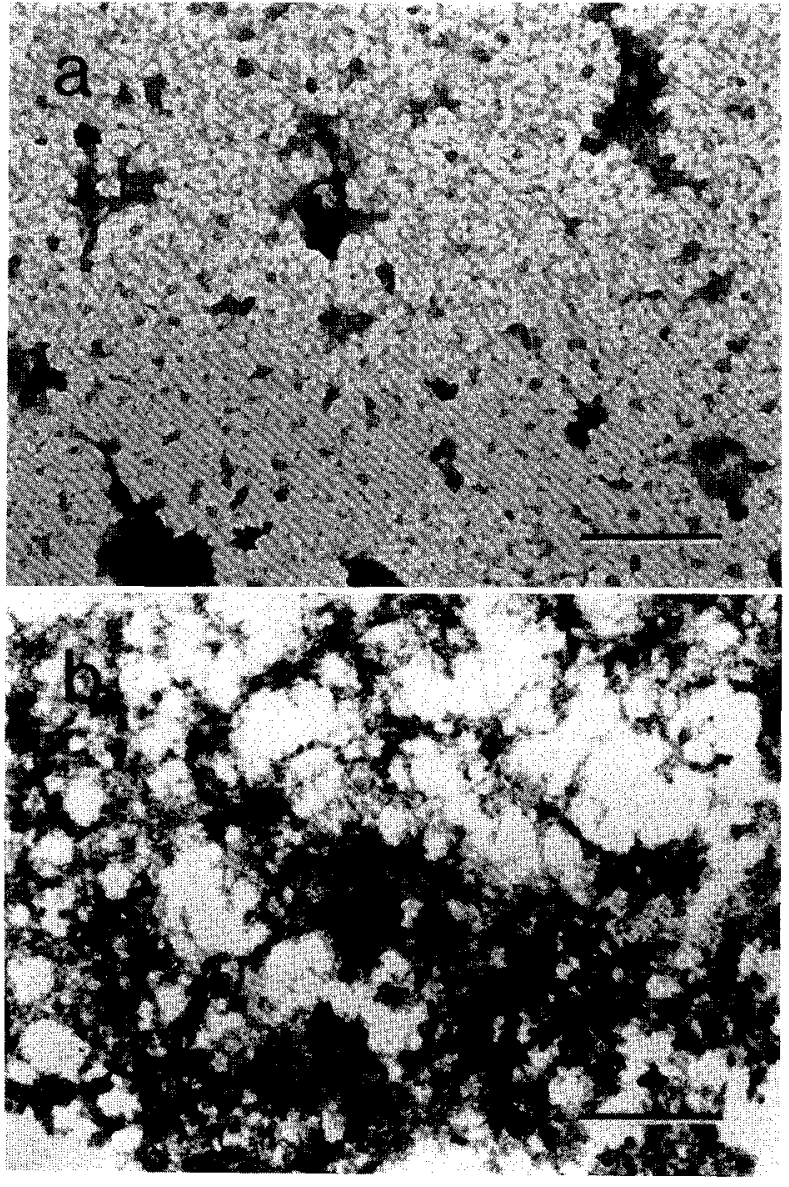

Fig. 5. Electron micrographs of $0.05 \%$ Triton-insoluble cytoskeletons isolated from MCF-7 cells. Negative staining was done on the cytoskeleton isolated from cells grown in monolayer cultures (a) or morphologically developing cells in collagen gels (b). Bar, $0.5 \mu \mathrm{m}$.

The invagination of cells into collagen gel as a cell mass and formation of three-dimensional cellular structures within it are accompanied by a significant change in cell shape as compared with the cell shape in monolayer cultures. Such change in cell shape has been suggested to be induced by the contraction of collagen gel (1). However, it is also possible that the contraction of the gel may be induced by the cells grown within it since no contraction of the gel is observed in the absence of cells. The cellular factors that can interact with collagen gel as an extracellular matrix and can regulate cell morphology are generally thought to be the cytoskeletal components such as microtubules, actin filament (3), or intermediate filaments (9). The present study demonstrated that MCF-7 cells forming three-dimensional cellular structures within collagen gels formed a less fine cytoskeletal network with a greater buoyant density as compared with the cytoskeleton in monolayered cells. The $0.05 \%$ Triton-insoluble cytoskeleton isolated from the morphologically developing cells was composed of 4 prominent components with apparent molecular sizes of 54-, 45-, 


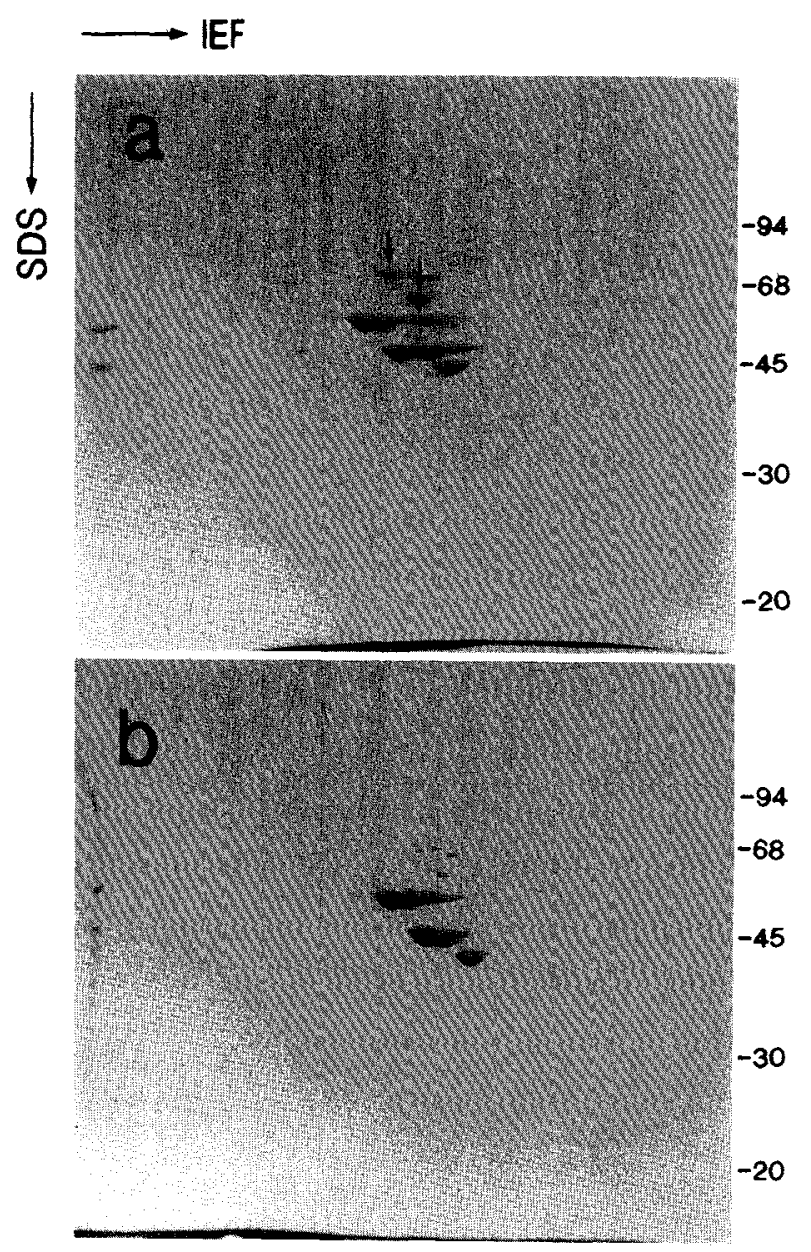

Fig. 6. Two-dimensional gel electrophoresis of the cytoskeletal components isolated from MCF-7 cells as $0.05 \%$ Triton-insoluble fraction. Coomassie blue-stained cytoskeletal components of cells grown in monolayer cultures (a), and cells forming cylindrical or domed cellular structures in collagen gels (b). Arrows indicate two distinct polypeptides significantly enriched in cells grown as a monolayer. Molecular sizes are indicated to the right in $\mathrm{kD}$.

$42-$, and $39-\mathrm{kD}$, and was virtually lacking in $65-$ and $80-\mathrm{kD}$ polypeptides found in the monolayered cells. The lack of these latter two polypeptides cannot attributed to their altered solubilities in the detergent since the relative amount of each of them detectable in the total polypeptide moiety is also very small. While the former 4 polypeptides were also insoluble in $0.5 \%$ Triton, the latter two polypeptides were soluble in the detergent at $0.5 \%$ (unpublished observation). It is conjectured that the coarser cytoskeletal network may enable cells to invaginate into the gel to form three-dimensional cellular structures within it, accompanied by a change in cell shape. In monolayer cultures of MCF-7 cells, a fine cytoskeletal network consisting of the $65-\mathrm{kD}$ and $80-\mathrm{kD}$ polypeptides in addition to the 4 polypeptides may be required for cells to spread in a flat layer over the solid plastic substratum. Hence, it is
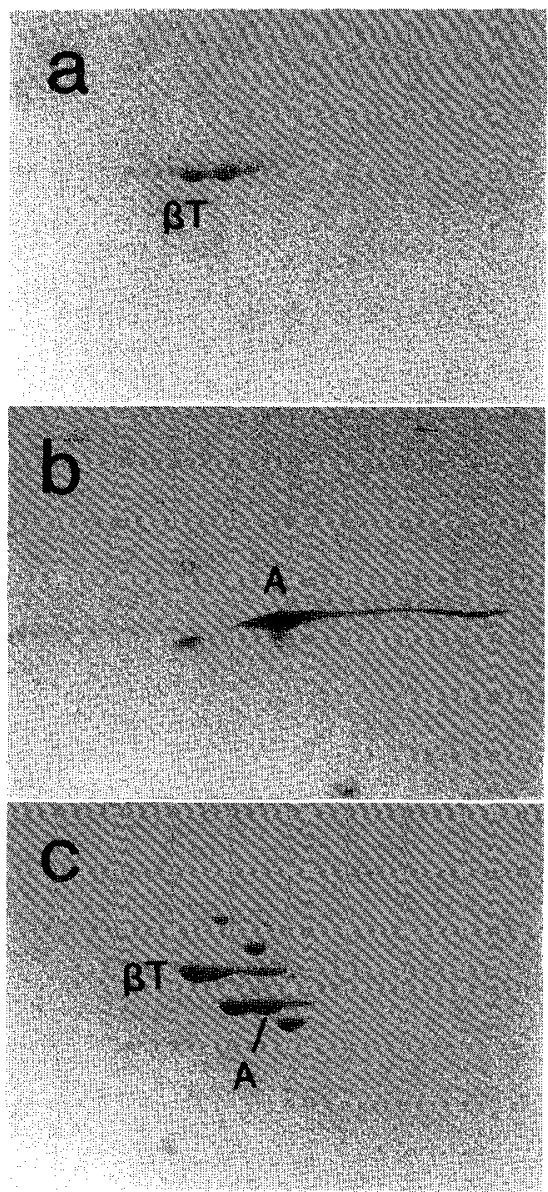

Fig. 7. Immunochemical identification of the cytoskeletal components. Coomassie blue-stained polypeptide after immunoprecipitation with monoclonal anti-tubulin ( $\beta$ chain) antibody of $0.05 \%$ Triton-insoluble cytoskeletal components isolated from MCF-7 cells in monolayer cultures (a). Immunostaining of polypeptide that reacted with a monoclonal anti-actin antibody (b). Coomassie bluestained cytoskeletal components isolated from MCF-7 cells in monolayer cultures (c). Polypeptide reactable with anti-tubulin ( $\beta$ chain) or anti-actin antibody is indicated as $\beta \mathrm{T}$ or $\mathrm{A}$, respectively.

speculated that the role of these two polypeptides are to interact with the other 4 polypeptides to form a fine cytoskeletal network.

Among the 4 prominent polypeptides found in the cells grown under either culture conditions, the $54-\mathrm{kD}$ and $42-\mathrm{kD}$ polypeptides are $\beta$-tubulin and actin, respectively, as judged by their reactivities with antibodies and their molecular sizes (22, 23 ). Except for the $54-\mathrm{kD}(\beta$-tubulin) and $42-\mathrm{kD}$ (actin) polypeptides, the $45-\mathrm{kD}$ and $39-\mathrm{kD}$ polypeptides and the two polypeptides which were specific for cells in monolayers failed to react with the antibodies used: anti-cytokeratins, anti-vimentin, and anti- $\alpha$-tubulin. The absence of vimentin in MCF-7 cells was in agreement with the previous finding (12). With respect to their mobilities on two-dimensional gels, the $45-\mathrm{kD}$ and $39-\mathrm{kD}$ polypeptides may correspond to cytoskeratin 18 

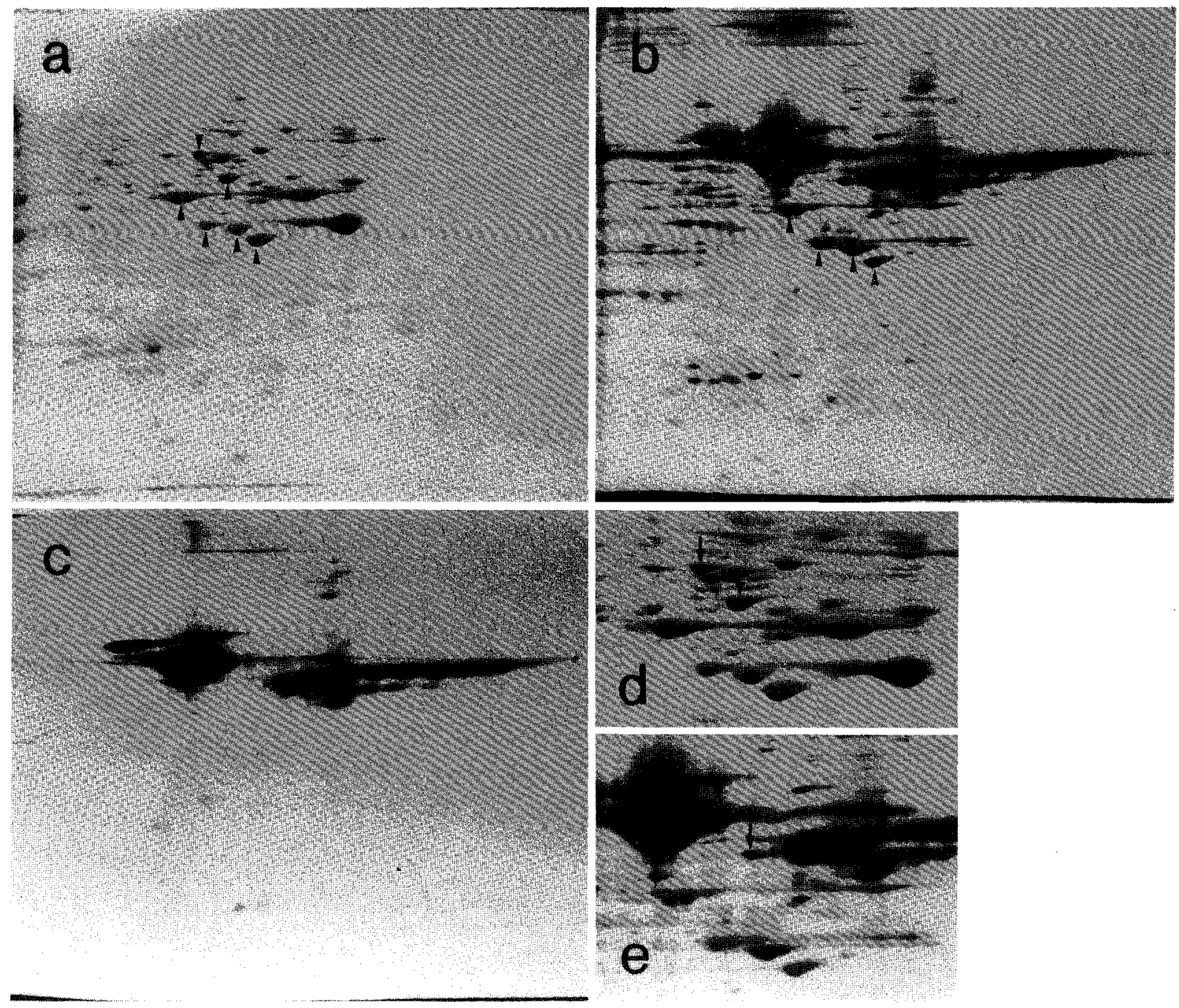

Fig. 8. Two-dimensional gel electrophoresis of the total polypeptides of MCF-7 cells. Coomassie blue-stained total polypeptides of cells grown as a monolayer (a). Silver-stained total polypeptides of morphologically developing cells within collagen gels (b). Silver-stained polypeptides derived from collagen gels without cells (c). Arrowheads in (a) and (b) indicate the $0.05 \%$ Triton-insoluble cytoskeletal polypeptides shown in Fig. 5. An enlargement (d) corresponding to the area containing the $0.05 \%$ Triton-insoluble cytoskeletal components in (a). An enlargement (e) corresponding to the area containing the $0.05 \%$ Triton-insoluble cytoskeletal components in (b). Arrows in (d) and (e) indicate the $80-\mathrm{kD}$ and 65 $\mathrm{kD}$ polypeptides.

(45-kD) and $19(40-\mathrm{kD})$, respectively (13). The other two polypeptides, the $65-\mathrm{kD}$ and $80-\mathrm{kD}$ ones, may not correspond to fimblin $(68-\mathrm{kD})$, or villin $(95 \mathrm{kD})(11)$. The latter polypeptide also has an apparent molecular size similar to that of a polypeptide found in brush borders of chicken small intestine epithelial cell (2) or to that of radixin $(82-\mathrm{kD})$ found at the cellto-cell adherens junction in various types of rat tissues, including small intestine (21). Further characterizations of the polypeptides, especially those that failed to be recognized by the antibodies used in the present study, will be required to clarify their possible roles in the regulation of cell shape and morphological development.
Acknowledgment. The authors thank Mr. Yoshiyasu Nakamura for his expert technical assistance.

\section{REFERENCES}

1. Bissell, M.J., LI, M.L., Chen, L.-H., and LeE, E.Y-H. (1987). Regulation of milk proteins in the mouse mammary epithelial cells by extracellular matrix and hormones. In Growth and Differentiation of Mammary Epithelial cells in Culture (J. Enami, and R.G. Ham, eds.). Japan Scientific Press, Tokyo, pp. $155-186$.

2. Bretscher, A. (1983). Purification of an 80,000-dalton protein that is a component of the isolated microvillus cytoskeleton, and its localization in nonmuscle cells. J. Cell Biol. 97: 
425-432.

3. CoHEN, C. (1979). Cell architecture and morphogenesis. I. The cytoskeletal proteins. Trends Biochem. Sci. 4: 73-77.

4. DeOme, K.B., Faulkin, L.J., Bern, H.A., and Blair, P.B. (1959). Development of mammary tumors from hyperplastic alveolar nodules transplanted into gland-free mammary fatpads of C3H mice. Cancer Res. 19: 515-520.

5. Emerman, J.T. and Pitelka, D.R. (1977). Maintenance and induction of morphological differentiation in dissociated mammary epithelium on floating collagen membranes. In Vitro 13: 316-328.

6. HsU, S.-M., RAINE, L., and FANGER, H. (1981). Use of avidinbiotin-peroxidase complex in immunoperoxidase techniques. $J$. Histochem. Cytochem. 29: 577-580.

7. ICHINOSE, R. and NANDI, S. (1964). Lobuloalveolar differentiation in mouse mammary tissues in vitro. Science 145: 496-497.

8. Kuroda, M. and PoRTeR, K.R. (1987). Cytoskeleton In Vitro: Preparation of isolated cytoskeletons with three-dimensional architecture. J. Biochem. 101: 1413-1427.

9. LAZARIDES, E. (1980). Intermediate filaments as mechanical integrators of cellular space. Nature 283: 249-256.

10. Matsudaira, P. (1987). Sequence from picomole quantities of proteins electroblotted onto polyvinylidene difluoride membranes. J. Biol. Chem. 262: 10035-10038.

11. Matsudatra, P., Mandelkow, E., Renner, W., Hesterberg, L.K., and WEBER, K. (1983). Role of fimblin and villin in determining the interfilament distances of actin bundles. Nature 301 : 209-214.

12. Miettinen, M., Lehto, V-P., and Virtanen, I. (1984). Antibodies to intermediate filament proteins in the diagnosis and classification of human tumors. Ultrastruct. Pathol. 7: 83-107.

13. Moll, R., Franke, W.W., Schlller, D.L., Geiger, B., and KrePler, R. (1982). The catalog of human cytokeratins: Patterns of expression in normal epithelia, tumors and cultured cells. Cell 31: 11-24.

14. OAKLEY, B.R., KIRSCH, D.R., and Morris, N.R. (1980). A simplified ultrasensitive silver stain for detecting proteins in polyacrylamide gels. Anal. Biochem. 105: 361-363.
15. O'FARRell, P.H. (1975). High resolution two-dimensional electrophoresis of proteins. J. Biol. Chem. 250: 4007-4021.

16. ORMERod, E.J., and RudLAND, P.S. (1982). Mammary gland morphogenesis in vitro: Formation of branched tubules in collagen gels by a cloned rat mammary cell line. Dev. Biol. 91: 360375 .

17. Takahashi, K., Kawahara, S., and Ono, T. (1990). Effects of growth factors and hormones on growth and morphological differentiation of human breast epithelial cells within collagen gel in serum-free medium. Jpn. J. Cancer Res. 81: 52-57.

18. ToneliI, Q.J., and SoroF, S. (1982). Induction of biochemical differentiation in three-dimensional collagen cultures of mammary epithelial cells from virgin mice. Differentiation 22: $195-200$.

19. Topper, Y.J., and FreEman, C.S. (1980). Multiple hormone interactions in the developmental biology of the mammary gland. Physiol. Rev. 60: 1049-1106.

20. Towbin, H., Staehelin, T., and Gordon, J. (1979). Electrophoretic transfer of proteins from polyacrylamide gels to nitrocellulose sheets. Procedure and some applications. Proc. Natl. Acad. Sci. U.S.A. 76: 4350-4357.

21. Tsukita, S., Hieda, Y., and Tsukita, S. (1989). A new 82-kD barbed end-capping protein (Radixin) localized in the cell-to-cell adherens junction: Purification and characterization. J. Cell Biol. 108: 2369-2382.

22. Valenzuela, P., Quiroga, M., Zaldivar, J., Rutter, J.W., Kirschner, M.W., and Cleveland, D.W. (1981). Nucleotide and corresponding amino acid sequences encoded by $a$ - and $\beta$ tubulin mRNAs. Nature 289: 650-655.

23. VANDEKerckhove, J., LeavitT, J., KaKunaGa, T., and WEBER, K. (1980). Coexpression of a mutant $\beta$-actin and the two normal $\beta$ - and $\gamma$-cytoplasmic actins in a stably transformed human cell line. Cell 22: 893-899.

24. Yang, J., Richards, J., Bowman, P., Guzman, R., Enami, J., McCormick, K., Hamamoto, S., Pitelka, D., and Nandi, S. (1979). Sustained growth and three-dimensional organisation of primary mammary tumour epithelial cells embedded in collagen gels. Proc. Natl. Acad. Sci. USA 76: 3401-3405.

(Received for publication, May 24, 1990 and in revised form, June 29, 1990) 